\title{
Improving the Use of Technology Enhanced Learning Environments in Higher Education in the UK: A Qualitative Visualization of Students' Views
}

\author{
Mark Kennedy \\ King's College-London, United Kingdom \\ Thomas J. Dunn \\ Bishop Grosseteste University, United Kingdom
}

\begin{abstract}
In recent years, the use of Technology Enhanced Learning (TEL) has risen exponentially throughout higher education in the UK. Whilst TEL is an umbrella term for a range of technologies, evidence suggests that in the UK, TEL is usually delivered via the medium of Virtual Learning Environments (VLEs) for the provision of lecture materials and additional content. An emerging literature has established both the pedagogical potential and students' perceived usefulness of TEL. However, researchers have yet to establish how the use of TEL via VLEs can be improved - a core requirement of establishing best practice. The current study sought to address this in a sample of 487 predominately undergraduate students. Content analysis revealed that views were overwhelmingly positive, but that students had clear views on what they wanted to see improved. Students expressed clear desires for the more consistent and more frequent use of TEL within lectures. Further, they felt that the potential of TEL to encourage and facilitate interactions, both within their University and with external stakeholders, has thus far gone unexploited. Implications for teaching practice and future research are discussed.
\end{abstract}

Keywords: Technology enhanced learning; Virtual learning environment; Student preferences; Higher education; E-learning

\section{Introduction}

In recent years, the use of Technology Enhanced Learning (TEL) in higher education has risen exponentially and has had three central drivers. First, there have been recent increases in governmental spending and influential changes in policy, such as the Higher Education Funding Council for England's (HEFCE) e-learning strategy (2005), revised e-learning strategy (2009) and the Higher Education Academy's (HEA) Benchmarking and Pathfinders initiatives (2006-09). Second, there is a recognized aspiration for Universities to be seen as innovative and up to date technologically (Kukulska-Hulme, 2015). Third, there is a perception that students, i.e., 'digital natives,' demand to be provided with advanced technology (Prensky, 2001).

In addition to steering investment, a key aspect of governmental influence has been to encourage institutions to take individual responsibility for the implementation of TEL - as part of an increasingly deregulated industry (Walker, Voce \& Jenkins, 2016). This has resulted in heterogeneity in the uptake of TEL (Selwyn, 2014). A recent review suggests that, broadly 
speaking, there may be greater heterogeneity within institutions than between them, with Universities as a whole tending to deliver TEL via the use of Virtual Learning Environments (VLEs) and allowing individual lecturers to populate them as they see fit (UCISA, 2016). These VLEs are used as a gateway to a range of different technologies, to one extent or another, such as online quizzes/revision aids, lecture recordings and/or slides, blogs/ discussion boards and other online resources. Interestingly, institutions in the UK seem to have been slow to uptake more novel forms of TEL, such as the use of gamification (Nacke \& Deterding, 2017). Adjacent to these types of technology provided by institutions, research shows that students also tend to create their own social media groups to discuss their studies, in addition to reflecting on their University experiences more generally (Selwyn, 2009).

Research thus far has mainly focused on the potential value of TEL (Henderson, Selwyn \& Aston, 2015) and the pedagogical advantages the use of TEL in higher education might confer (e.g., Conole, 2014). However, questions have been raised around the extent to which the potential benefits reflect real advantages (Olofsson \& Lindberg, Selwyn, 2010). Consequently, there is a recognized growing need to establish its impact (Englund, Olofsson \& Price, 2017). One important metric is the extent to which students are satisfied with TEL (HEFCE, 2009). Internationally, there have been some attempts to bridge this gap (e.g., Henderson, Selwyn \& Aston, 2015), but less is known within the UK.

Extant evidence shows conceptions surrounding the 'digital native', as individuals who are immersed in technology and express a strong need for innovation through technology (Prensky, 2001), should be treated with caution (Pechenkina \& Aeschliman, 2017). Specifically, students may be hesitant to engage with new technologies (Thompson, 2013), technology is often used for communication (Bauerlein, 2008) rather than innovation, and engagement with TEL is generally low (Kennedy et al., 2008; Thompson, 2013). The finding that students frequently opt to not engage with TEL, in light of an apparent desire for it, strongly suggests that there is a gap in understanding precisely what students want TEL to be used for.

In order to help establish best practice and meet student needs, research should focus on what TEL should be used for, rather than simply what it is currently used for. It is here where the value of the current study lays, by going beyond what students see the value of TEL to be and to explore what value they want TEL to add to their education. Consequently, the current study aimed to build upon previous studies and to provide a sense of both what students' views are on TEL currently and how they would like to see it improved for the future. The current study focused on the most commonly delivered forms of TEL; lecture slides, recordings (lectures), additional content, blogs, discussion forums and social media groups. The specific research questions were as follows:

- What do students see as the day to day usefulness of TEL?

- How would they like to see the use of TEL being improved upon?

- What can educators do to improve the ways in which TEL is delivered, particularly via VLEs?

\section{Methodology}

These data were collected by using two open-ended questions as part of a wider TEL research project. Data were collected during the 2016 academic year from a large UK higher education 
institution with an undergraduate cohort of 16,150. Participants were recruited via an online recruitment process and were awarded research credits for their time. Owing to the channel of recruitment being through the department of psychology, all respondents were undertaking psychology or psychology-related courses. The self-selected sample of students comprised a total of 487 participants (see Table 1 for a breakdown of respondent characteristics). Students were asked to estimate their average grade, the distribution of grades for the sample can be seen in Figure 1.

Table 1. Characteristics of Respondents

\begin{tabular}{lll}
\hline & $N$ & $\%$ \\
\hline Gender & & \\
Females & 419 & 85.8 \\
Males & 64 & 13.1 \\
Age & & \\
Mean & 19.8 & \\
SD & 2.6 & 2.3 \\
$>25$ years & 11 & \\
Year of study & & 30.4 \\
First & 146 & 43.7 \\
Second & 210 & 25.9 \\
$\quad$ Third & 125 & \\
Domicile status & & 90.5 \\
$\quad$ National & 428 & 9.5 \\
International & 45 & \\
\hline
\end{tabular}

Note: Not all totals will sum to 487 due to missing data

Data arose from two open response questionnaire items. The first asked participants 'what are the benefits of Technology Enhanced Learning to you?', the second asked 'In which ways could the delivery of Technology Enhanced Learning be improved?'. Students were introduced to aspects of TEL via the following statement: "TEL includes both the use of technology outside of the classroom (e.g., use of the Virtual Learning Environment for accessing lecture slides, lecture recordings, additional content posted by lecturers, blogs and so on) and within the classroom (e.g., electronic response systems (clickers/ zappers), in-lecture social media and so on)". 


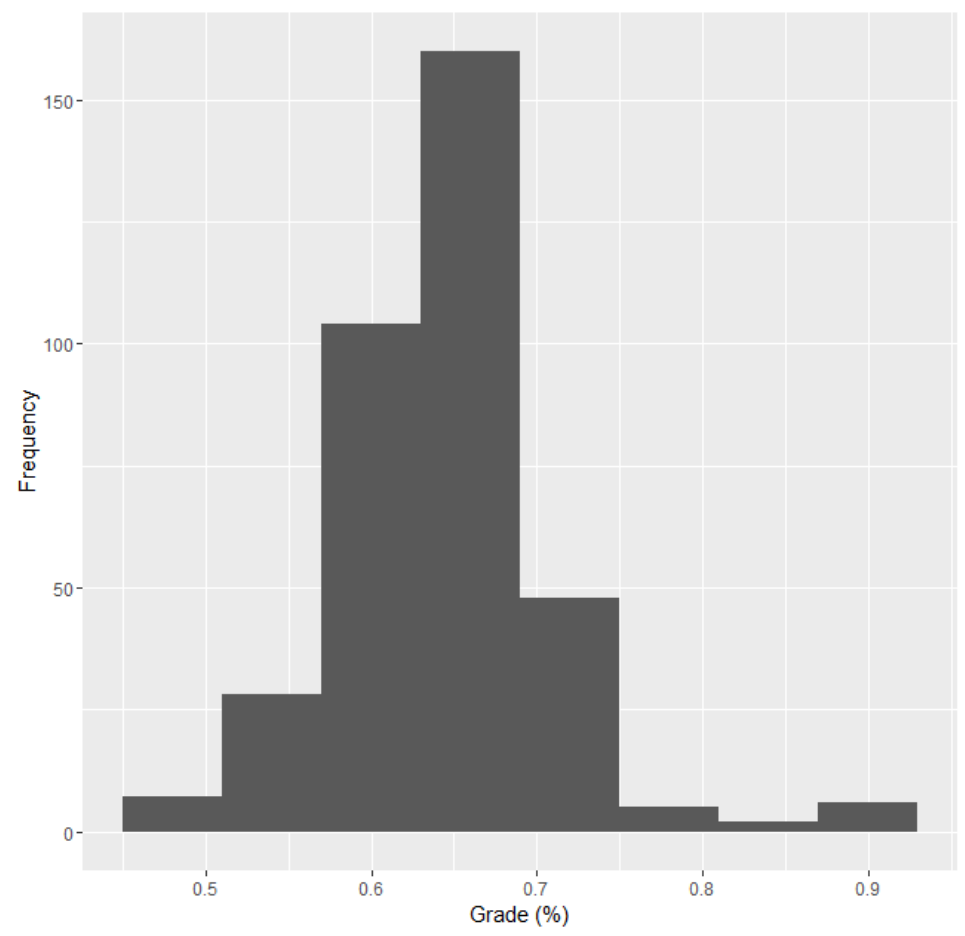

Figure 1. Distribution of Sample Grades

Our aims were to describe the phenomenon observed from a positivistic perspective, rather than a social constructionist perspective. Consequently, content analysis was deemed most appropriate (Rosengren, 1981). Rather than starting off with an a priori coding strategy, we intended to allow the categories to emerge naturally from the data and so, our approach is best described as "conventional content analysis" (Kondracki \& Wellman, 2002). Specifically, we followed the steps provided by Hsieh and Shannon (2005):

Our first step was to read and re-read the body of text, as to 'achieve immersion' and to gain an understanding of the responses we received. Our second step was to code the corpus of text word by word, using R software (Fellows, 2014). Initially, a process of word cropping was employed which reduced the data to include only the most relevant and useful words. This involved removing punctuation, numbers, stop words (e.g., 'and', 'the', 'a'), and word stems (e.g., 'ing', 'es', 'er', 'ed'). Following this, we broke the data down into the most commonly appearing words (see Figures 2 and 3 ). As a third step, semantically similar words (e.g., access, accessibility) were grouped in order to form specific categories. The fourth step involved organizing the derived codes into meaningful clusters. These clusters were then organized by how frequently they appeared (Figure 2). This process was repeated for both questions separately.

\section{Results}

Owing to a disparity in the number of male and female participants, analysis was first carried out to test for any differences in terms of patterns in responding. Results showed that the top five word responses were a very close match between males and females with the exception of only one word stem (lectures vs. lecturing). Additionally, there was no statistically significant 
difference in terms of relative frequencies of the top five words between males and females $\left(\chi^{2}(8, N=571)=10, p=0.27\right)$.

In order to clearly illustrate the content of responses for each question and their relative frequencies, wordclouds (also known as tag clouds or weighted lists) were created using $R$ statistical software. The wordcloud for question 1 can be seen in Figure 2 and the wordcloud for question 2 can be seen in Figure 3.For each question, the results are presented in order of how commonly they emerged.

Question 1: 'What are the Benefits of Technology Enhanced Learning to You?'

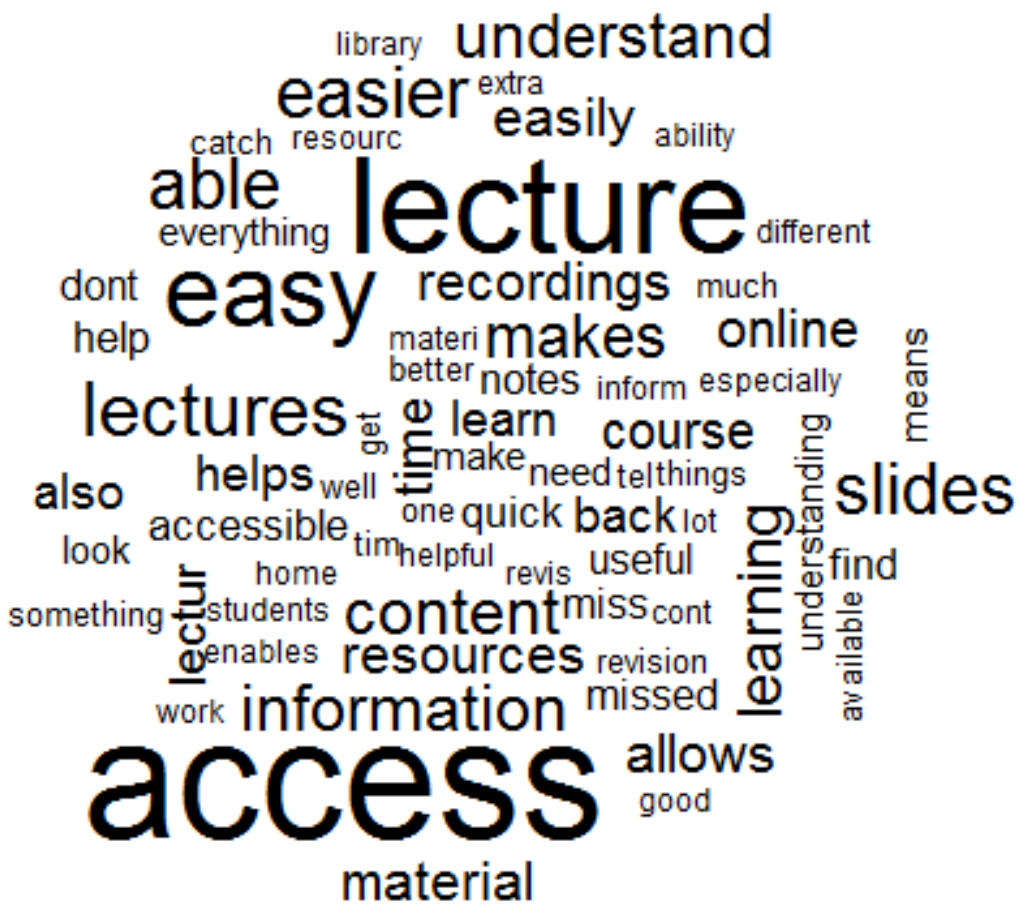

Figure 2. Word Cloud of Responses to Question 1

The most frequent response type related to the ease of access to information and resources that TEL allows efficient access to resources; 'easily accessible all in one place, less time consuming than finding books in libraries etc.' (5). This comprised several core components. First, providing direct access to distal resources that traditionally students would source themselves e.g., from libraries at other Universities. This seemed particularly important for students with additional needs:

'I am ill a lot due to disability so it is important for me to be able to access content remotely at home' (285).

Second, comments reflected students being able to access resources relevant to the course as a whole in a single location 'it also enables all my main core areas of the course to be in one place i.e. blackboard' (12). Third, students described the increased efficiency TEL affords; allowing students to spend time engaging with core materials which would have otherwise 
been spent locating them 'easy access which saves time and gives time back to learning' (18). Fourth, students commented on how placing resources online means that more students can access them contemporaneously - compared to traditional books which may only exist in limited supply 'it also means that more people can use these resources at once' (24). Fifth, students commented on TEL allowing them to engage with learning on a range of devices 'It allows me to easily access lecture material to be able to review and learn the content for exams' (55) and in a range of locations 'easy to access from home as I commute' (41).

However, students also noted important potential caveats to access. Specifically, there were concerns raised about whether ease of access, particularly to lecture recordings, might act as a disincentive to attending the lectures themselves:

'I think people who attend the lecture should have access to the recordings (but only if they turned up to that session)... otherwise no one will turn up to the lecture' (17).

The second most common response type reflected how TEL is changing the nature of the traditional lecture. Inside of class, students felt that TEL was changing lectures positively. By using innovative approaches, such as the use of Twitter feeds and interactive quizzes, students felt that lectures had become 'more interesting' (472), 'fun' (24) and ultimately makes the content 'more memorable' (24). Similarly, students felt that posting lecture slides online allowed them to attenuate to a greater degree in class:

'Having lecture slides and recordings online allows me to go over the issues raised in lectures and make more in-depth notes' (438).

Students also commented on how, rather than a one-off event, lectures (if recorded) become an ongoing resource. Students appeared to welcome how TEL prevents them from being left behind' (435) and allows them to recap information that they have either missed, or found difficult to understand initially - allowing students to take learning at their 'own pace' (479).

The third most common response type centered on the lecture slides themselves. Not only did students appreciate online lecture slides as an ongoing resource, they also valued them being uploaded in advance of lectures. This enabled students to print them out beforehand and to use them as a framework for making notes. This seemed to be particularly important for students who otherwise might struggle:

'access to lecture notes before and after lecture (I am slow in processing information and so this helps me understand the lecture better)' (163).

The fourth most common response type revolved around content/information. In addition to ease of access to content/information, students raised two further issues. First, students commented on the capacity for TEL to place 'lots of content' (224) at their fingertips, enabling them to engage with a wider range of resources. Second, they also commented on the in-built structure that accessing resources online can provide. In other words, instead of students searching haphazardly for information that may be relevant, TEL allows them to approach this in a 'more structured' (33) manner.

The fifth most common response type was that TEL, especially innovative techniques such as interactive quizzes and tools designed to provide immediate feedback (for example TurningPoint) help students understand and learn. 
'TEL means I can receive immediate feedback in class/lectures about how well I am understanding the content, which can make me feel more confident about my progress in a module' (23).

Students also commented on how increasing use of TEL 'allow[s] for more active engagement' (229). Furthermore, by allowing students to engage in alternative ways, using TEL can overcome some of the barriers students may have to asking questions during lectures:

'It allows me to take an active part in my own learning (rather than passively listen to lectures). I am able to learn the content at my own pace and in my own time-very flexible. I sometimes I am too embarrassed to ask questions during the lecture or online but TEL allows me to find the answer to my own question' (119).

\section{Question 2: 'In Which Ways Could the Delivery of Technology Enhanced Learning be Improved?'}

The next question built upon question 1 by asking the participants, how TEL could be improved. The corresponding wordcloud can be seen in Figure 3. From this, it is apparent that more content be made available to students, specifically recordings of lectures. This is something most FE institutions have the resources for yet might not utilize fully. Again, the five most common unique response types are described below.

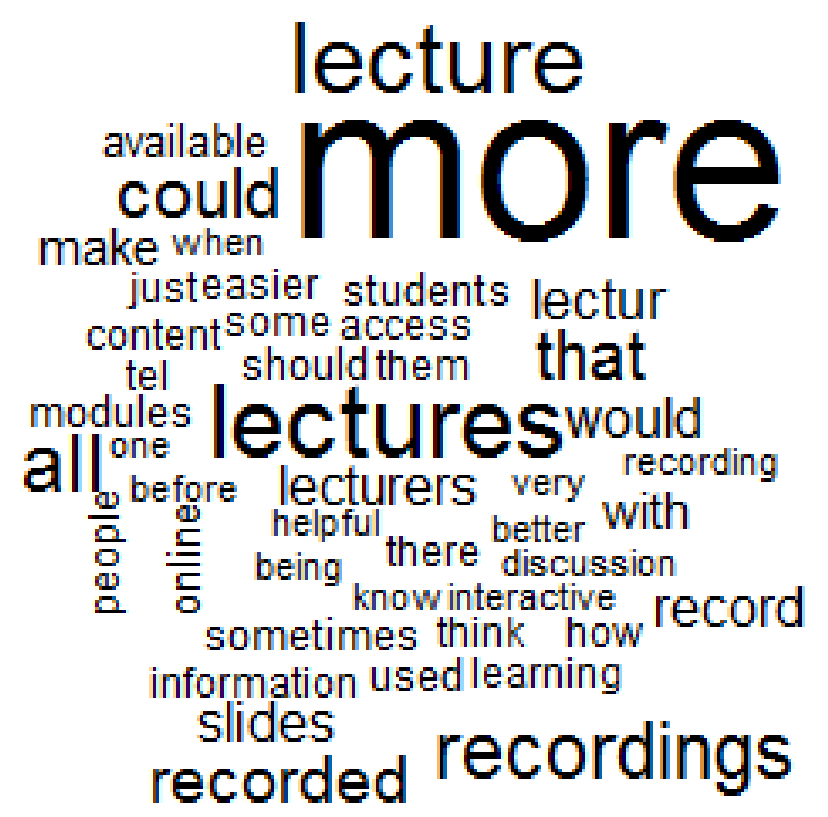

Figure 3. Word Cloud of Responses to Question 2

The most common response type was simply that students desired more TEL; 'in every possible way - there needs to be more of it' (30). This notion of 'more' TEL comprised several core components. 
First, students wanted the use of TEL to be 'more widely used' (4) and delivered in a more consistent, 'uniform' (118) manner across their course. In particular, given that so many students mentioned the perceived usefulness of lecture recordings, that they should be used for most/all modules; 'I wish that more lectures would provide lecture recordings online' (23). Students also suggested that forums, usually module specific, should be open for 'students to be able to ask important questions on... all year round' (86).

Second, students wanted there to be more resources signposted to them. For example, students mentioned that it would be useful to direct them towards wider readings and that supplementary information could be made available, perhaps 'emphasizing the use of videos' (10). Another example is that rather than link relevant studies, lecturers could 'have more resources that explain theories/research instead of just links to relevant studies' (34), thus providing alternative explanations when students struggled to understand the one provided by the lecturer. Central to this, however, was that it should be clear to students what content is available and why it is important to them; 'not just putting up content but also explaining it' (122).

The second most common response type revolved around the integration of TEL into lectures themselves. First, students wanted TEL to be used more often, particularly within lectures, which would help consolidate their learning; 'more interactive tasks during lectures so information is processed more accurately' (9). Furthermore, by delivering content in a more 'dynamic way', for instance using videos, education 'usually becomes more interesting' (40).

Second, students suggested that the potential of TEL can be harnessed to allow for greater levels of engagement, both within lectures and outside of them. This engagement was with lecturers, other students and also with external bodies; 'more ways to interact with lecturers/people with knowledge about subject[s]' (16). Students felt that peer engagement could be facilitated both within lectures and outside of them. A number of students reported that TEL has the opportunity to create 'more social aspects between teacher and student' (233) within lectures. They also stated the pedagogical value of such interactions:

'it's easier to approach, ask and state one's opinion and there's greater number of people engaging [sic] in discussion' (194).

Outside of lectures, students felt that TEL has the capacity to facilitate engagement with other students:

'course blogs and discussions would also increase involvement in the course and would probably make people more motivated' (406).

Students also felt that TEL has the potential to encourage liaison with professionals, outside of the University context:

In a way that it could offer more sociable surrounding, gathering professionals and students in exchangeing [sic] ideas and opinions' (135).

The third most common response type was "could/ should" - representing the non-specific potential that TEL has to students. Specifically, students commented that TEL could be presented in varying degrees of difficulty; 'in order to challenge students even further' (232). 
In doing so, rather than using online content as a means of consolidating the learning of set content, it could push them beyond this and offer greater challenges. There was also a call for greater integration with a broader range of devices, both in terms of file types that can be used on different computer operating systems; 'could be file types that work across both windows and mac (eg. use .ppt/.pptx instead of .key)' (186), but also for mobile support more generally; 'more things be integrated to use on mobile/tablets (mobile view/navigations)' (485).

The fourth most common response type was students discussing the use of lecture slides. Such comments mainly centered around the quality of the slides and their integration with recordings and other content. Specifically, students requested 'clearer slides with more details' (53). Rather than simply record the lecturer talking, students expressed a clear preference for technologies which present the slides contemporaneously with the lecture slides (e.g., Panopto); 'helpful to hear what the lecturer said with the corresponding slides' (62). This also related to how 'prompt' (67) content - particularly lecture slides and recordings are posted online - with students preferring lecture slides to be available to them well in advance of lectures.

The fifth most common response type was concerned with the ease of use/ accessibility of TEL. This largely revolved around lecture recordings; 'recordings could be of higher quality' (4). This notion of access also included the interfaces themselves. Specifically, rather than have multiple online systems to navigate, students expressed a desire for these to be consolidated into a single format, thus 'minimizing [sic] the quantity of different places for everything' (43). Students also commented that if TEL is to be embraced, both students and staff should receive some training in order to access them appropriately:

'more training for those administering and clear instructions on how to use the technology for students' (153).

\section{Discussion}

In this large scale qualitative study, the aim was to explore both students' perceived benefits of TEL and also to try and gain some understanding of what value TEL can add going forwards. The current paper adds to the growing literature demonstrating that the integration of TEL into higher education has been well received by students (e.g., Henderson, Selwyn \& Aston, 2015; Walker, Voce \& Jenkins, 2016). Specifically, the current study has shown that above all else, what students value about TEL is the ease of access to both core and wider resources that it provides. This increase of access allowed students to locate course-wide materials in a single location. It also allowed students to spend time engaging with resources, which would have historically been spent on locating them. Alongside this, students also appeared to value the ways in which TEL has changed the nature of the traditional lectures. Within lectures themselves, students spoke about increased levels of interaction that TEL allows, with the lecturer as well as other students. They also expressed how innovative uses of TEL, such as the use of Twitter feeds and digital quizzes, can make lectures more engaging, fun and interesting. Through the use of recordings, TEL has also changed lectures from one-off events to ongoing resources; an approach which appeared to help with revision and going over any points which may have been missed - this latter notion appearing to be highly valued by students who might struggle initially. 
In a similar fashion to the recent study conducted by Henderson, Selwyn and Aston (2015), many of these perceived benefits would be better conceptualized as logistic in nature, rather than enhancing learning directly. Similar also to this study was that many of the perceived benefits (e.g., not having to source independently or otherwise engage with long portions of text) could be argued to - at least historically - constitute core aspects of the academic endeavor (Lairio, Puukari \& Kuovo, 2013). However, this did not apply to all comments and many were pedagogical in nature. TEL was seen as a means of facilitating interaction and engagement - both with staff/students and also with relevant content and a useful means of providing immediate feedback. In particular, this increased access and allowance for each student to learn at their own pace represents an important opportunity to facilitate widening access to higher education (Dell, Newton \& Petroff, 2016). In more general terms, the current paper adds to the literature illustrating both how intertwined TEL is in higher education and how it has transformed higher learning (e.g., Brown, Anderson \& Murray, 2007). Where the current study adds to the extant literature is that it provides clear directions for the future use of TEL in higher education. There were a number of findings of note.

First, there was a clear desire for more TEL to be used. In line with previous studies (Browne et al., 2008; Flavin, 2016), whether TEL is used in lectures and the specific technologies employed (if any) are heterogeneous and not always consistent. Students expressed a clear desire for increased uniformity. In particular, students had a preference that all lectures should be recorded. They also expressed a strong desire for this uniformity to apply to the software itself. Rather than simply recording the lecturer speaking, students instead expressed a clear preference for technologies which merge lecture slides and audio contemporaneously (for example Panopto software). This also applied to the use of TEL within lectures themselves; with students demonstrating a clear desire for TEL to be used more for encouraging interactions between the lecturer and themselves and one another.

Second, students expressed a clear wish for an increase in additional resources and wider reading materials available to them. Rather than simply a need for relevant articles and so on being posted, students asked for more explanatory content. For instance, alternative explanations of a certain concept were requested, for when students either struggled to understand the initial explanation, or if they desire a more rounded understanding. However, it was also clear that simply increasing volume in and of itself would be insufficient. Instead, students expressed a desire for clear signposting to such resources and some clarification of what these resources were and what use they might be.

Third, students suggested a more novel use of TEL in higher education. In addition to helping to facilitate interactions inside of University, that TEL should be used as a means of encouraging more interactions with external sources, i.e., knowledgeable persons outside of the University, for instance practitioners and policymakers. Whilst many Universities do endeavor to create some type of communication with external persons or organizations as part of a wider program, the suggestion that this could be integrated with traditional lectures is a novel and potentially interesting and useful avenue to explore. This finding is perhaps not surprising, given the assertion that communication is a core feature of the technologies used by students more generally (Bauerlein, 2008). However, research suggests that the potential for communication offered by technology has yet to be exploited by education (UCISA, 2016). Consequently, it is clear from the current findings that if educators seek to increase student satisfaction with TEL, and teaching more generally, technology should be used to facilitate interactions. 
It should also be pointed out that students mentioned two important caveats to the use of TEL. First, students noted that if they are to be expected to engage with multiple pieces of software that are new to them that they (and occasionally the lectures themselves) had not received any training or direction in their use. This was consequently seen as an important barrier to the efficacy of TEL. Second, students were also keen to state that TEL is not an end in and of itself, and that TEL is used best as a means to greater engagement and learning:

'Don't be too dependent on slide shows- just reading off the slides makes it pointless and boring going to the lecture' (272).

One strength of the study is that rather than rely on pedagogical value of TEL in principle, or in abstract terms, it instead directly assesses students' experiences (Mackaskill \& Denovan, 2013). Strengths of the study include the relatively large sample size and our epistemological approach. Qualitative research has historically been criticized by some as being perceived to lack reliability and results can often be difficult to generalize. However, by adopting a positivistic approach to the analysis, our findings are grounded in real data, rather than having been interpreted. Also, by opting for a large sample, particularly for qualitative research, we hope that our results may be more readily generalized. However, the study is not without limitations. Most notably, the students were all recruited from within a single institution. Consequently, their experiences may be less diverse than if they were recruited from a range of Universities. However, there was marked heterogeneity in the types of TEL that students were exposed to across their course. As the sample was a general student cohort, the issues raised may not necessarily apply readily to specific minority groups, such as international students and older students. There is a another, perhaps more important caveat to research focusing on student views; whilst students may feel that certain provisions or actions are helpful, this in and of itself does not establish their pedagogical value (Bauerlein, 2008; Selwyn, 2016). Surprisingly, there is scarce research focusing on providing empirical evidence for what contribution a student's engagement with TEL makes to their grade classifications. Consequently, future research should aim to fill this gap and to perform similar research investigating whether minority student groups have other/ dissimilar needs and requirements

\section{Conclusion}

Our results support five specific recommendations for educators using technology enhanced virtual learning environments:

- TEL/VLE content should be consistent across modules. Both in terms of what is on offer (e.g., recorded lectures) and also how it is to be delivered (e.g., standard software packages). This was seen as particularly relevant for mobile platforms.

- TEL should be used more frequently within lectures, in order to enhance communication between students themselves and also with the lecturer.

- VLEs content should be more focused. Specifically, rather than simply a deposit for journal articles and so on, content should be made explicitly relevant and more explanatory content should be added, such as links to videos of external sources explaining concepts.

- TEL should be used as a means of building links with external groups/ individuals, both within lectures and outside of them. 
- Staff should be well trained on the software they are expected to use.

To summarize, VLE content and TEL more generally appear to be valued by students for its ability to provide quick and efficient access to resources/ course-wide content, maximize time spent learning (rather than searching), allowing learners to go at their own pace and its capacity for making learning more engaging and fun. Furthermore, TEL was praised as playing a key role in widening access to education for students with disabilities, childcare responsibilities and those who spend time commuting. However, students clearly felt that TEL provision could be improved and that TEL was sometimes present simply because it is expected. Going forward, staff in Higher Education should focus on utilizing TEL as a means to multiple ends, rather than simply an end itself.

\section{References}

Bauerlein, M. (2008). The dumbest generation: How the digital age stupefies young Americans and jeopardizes our future (or, don't trust anyone under 30). London: Penguin.

Browne, T., Hewitt, R., Jenkins, M., \& Walker, R. (2008). 2008 Survey of Technology Enhanced Learning for higher education in the UK. ALT-C 2008: Rethinking the digital divide.

Conole, G. (2014). The use of technology in distance education. Online distance education: Towards a research agenda, 217-236.

Dell, A. G., Newton, D. A., \& Petroff, J. G. (2016). Assistive technology in the classroom: Enhancing the school experiences of students with disabilities. Pearson.

Englund, C., Olofsson, A. D., \& Price, L. (2017). Teaching with technology in higher education: understanding conceptual change and development in practice. Higher Education Research \& Development, 36(1), 73-87.

Fellows (2014). Wordcloud Package. Retrieved from CRAN: https://cran.rproject.org/web/packages/wordcloud/index.html

Henderson, M., Selwyn, N., \& Aston, R. (2015). What works and why? Student perceptions of 'useful' digital technology in university teaching and learning. Studies in Higher Education, 1-13.

Higher Education Academy. (2008). e-Learning benchmarking and pathfinder programme 2005-2008: an overview. Retrieved from http://www.heacademy.ac.uk/resources/detail/learningandtech/bandpglossyfinal_upda te19mar09

Higher Education Academy. (2009). Transforming higher education through technologyenhanced learning. Retrieved from http://www.heacademy.ac.uk/resources/detail/learningandtech/transforming_he_thro ugh_technology_enhanced_learning

Higher Education Funding Council for England. (2005).HEFCE strategy for e-learning. Retrieved from http://www.hefce.ac.uk/pubs/hefce/2005/05_12/

Higher Education Funding Council for England. (2009). Enhancing learning and teaching through the use of technology: a revised approach to HEFCE's strategy for e-learning. Retrieved from http://www.hefce.ac.uk/pubs/hefce/2009/09_12/09_12.pdf 
Hsieh, H. F., \& Shannon, S. E. (2005). Three approaches to qualitative content analysis. Qualitative health research, 15(9), 1277-1288.

Kennedy, G., Dalgarno, B., Bennett, S., Judd, T., Gray, K., \& Chang, R. (2008). Immigrants and natives: Investigating differences between staff and students' use of technology. Hello! Where are you in the landscape of educational technology? Proceedings ASCILITE Melbourne 2008 (pp. 484-492). Melbourne: ASCLITE.

Kondracki, N. L., \& Wellman, N. S. (2002). Content analysis: Review of methods and their applications in nutrition education. Journal of Nutrition Education and Behavior, 34, 224230.

Lairio, M., Puukari, S., \& Kouvo, A. (2013). Studying at university as part of student life and identity construction. Scandinavian Journal of Educational Research, 57(2), 115-131.

Kukulska-Hulme, A. (2012). How should the higher education workforce adapt to advancements in technology for teaching and learning? The Internet and Higher Education, 15(4), 247-254.

Macaskill, A., \& Denovan, A. (2013). Developing autonomous learning in first year university students using perspectives from positive psychology. Studies in Higher Education, 38(1), 124-142.

Nacke, L. E., \& Deterding, S. (2017). The maturing of gamification research. Computers in Human Behavior, 71, 450-454.

Olofsson, A. D., \& Lindberg, J. O. (2014). Introduction. Technology, Pedagogy and Education, 23 (3), 285-291.

Pechenkina, E., \& Aeschliman, C. (2017). What Do Students Want? Making Sense of Student Preferences in Technology-Enhanced Learning. Contemporary Educational Technology, 8(1), 26-39.

Prensky, M. (2001). Digital natives, digital immigrants. On the horizon, 9(5), 1-6.

Rosengren, K. E. (1981). Advances in Scandinavia content analysis: An introduction. In K. E. Rosengren (Ed.), Advances in content analysis (pp. 9-19). Beverly Hills, CA: Sage.

Selwyn, N. (2010). Looking beyond learning: Notes towards the critical study of educational technology. Journal of Computer Assisted Learning, 26(1), 65-73.

Selwyn, N. (2009). Faceworking: Exploring students' education-related use of Facebook. Learning, media and technology, 34(2), 157-174. doi:http://dx.doi.org/10.1080/ 17439880902923622

Selwyn, N. (2016). Minding our language: why education and technology is full of bullshit...and what might be done about it. Learning, Media \& Technology, 41(3), 437-443. doi:http://dx.doi.org/10.1080/17439884.2015.1012523

Thompson, P. (2013). The digital natives as learners: Technology use patterns and approaches to learning. Computers \& Education, 65, 12-33. doi:http://dx.doi.org/10.1016/j. compedu.2012.12.022

UCISA., 2016. Survey of Technology Enhanced Learning for higher education in the UK. Retrieved from https://www.ucisa.ac.uk//media/Files/publications/surveys/TEL\%20Survey\%202016_Nov16 
Walker, R., Voce, J., \& Jenkins, M. (2016). Charting the development of technology-enhanced learning developments across the UK higher education sector: A longitudinal perspective (2001-2012). Interactive Learning Environments, 24(3), 438-455.

Correspondence: Mark Kennedy, Department of Child \& Adolescent Psychiatry, Institute of Psychiatry, Psychology and Neuroscience, King's College London, United Kingdom 